\title{
Obtaining more accurate and reliable information from adolescents regarding STI/HIV risk behaviors
}

\author{
Barbara Mensch \\ Population Council \\ Paul C. Hewett \\ Population Council
}

Follow this and additional works at: https://knowledgecommons.popcouncil.org/departments_sbsr-pgy

Part of the Demography, Population, and Ecology Commons, Family, Life Course, and Society Commons, Gender and Sexuality Commons, International Public Health Commons, Medicine and Health Commons, and the Sociology of Culture Commons

How does access to this work benefit you? Let us know!

\section{Recommended Citation}

Mensch, Barbara and Paul C. Hewett. 2007. "Obtaining more accurate and reliable information from adolescents regarding STI/HIV risk behaviors," Promoting Healthy, Safe, and Productive Transitions to Adulthood Brief no. 25. New York: Population Council. 


\section{Obtaining more accurate and reliable information from adolescents regarding STI/HIV risk behaviors}

\section{Prepared by Barbara S. Mensch and Paul C. Hewett}

\section{Self-reporting of sensitive behaviors leads to an} incomplete picture of adolescent STI/HIV risk

Understanding the dynamics of transmission of HIV and sexually transmitted inflections (STIs) in developing countries is seriously compromised by unreliable data on sexual and other risk behaviors. Epidemiological studies in Africa have observed little association between respondents' self-reported risky sexual behavior and their HIV status (Buvé et al. 2001; Glynn et al. 2001). Such puzzling findings have led some scientists to question the conventional explanation for the African AIDS epidemic and to suggest instead that HIV is more likely to be transmitted via medical injections with contaminated needles than by risky sexual behavior (Brewer et al. 2003; Gisselquist et al. 2003; Gisselquist and Potterat 2003). A number of researchers have investigated the reliability and validity of survey data collected in developing countries (Blanc and Rutenberg 1990; Blanc and Way 1998; Curtis and Sutherland 2004; Eggleston et al. 2000; Gregson et al. 2004; Lagarde et al. 1995; Nnko et al. 2004; Zaba et al. 2004). Although many acknowledge that reporting of sexual behavior is problematic, few have either investigated the ways in which the data collection process may be flawed or explored techniques to improve data accuracy (Gregson et al. 2002 and Plummer et al. 2004 are notable exceptions).

Given the importance of this issue, a technical meeting was convened in 2003 on "Measurement of Trends in Sexual Behaviour," co-sponsored by the London School of Hygiene

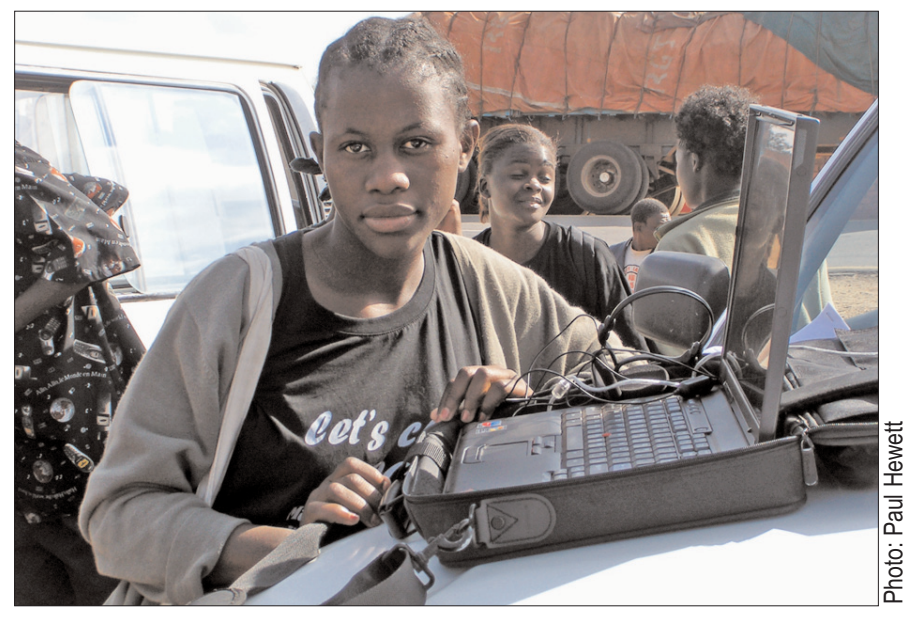

Results from studies in some developing countries indicate that computerized interviewing generally provides higher reporting of stigmatized risk behaviors than standard face-to-face interviews.

and Tropical Medicine, UNAIDS, WHO, and the MEASURE Project. Although the goal was to develop recommendations for measuring and monitoring trends in sexual behavior, no simple guidelines emerged (see Cleland et al. 2004). The participants' main conclusion was that more studies were needed before researchers could determine the best method (or methods) for collecting data on sexual behavior.

\section{Computerized survey interviewing}

To investigate the quality of self-reported data on sexual behavior, Population Council researchers recently conducted a 
study in a rural district of Malawi. As part of a householdbased survey of adolescents, they implemented a randomized experiment to assess whether audio computer-assisted selfinterviewing (ACASI) produces more valid data on sexual behavior than face-to-face interviews, the traditional method of survey research. ACASI, a technique designed in the United States to collect data on sensitive behaviors, relies on computer administration of surveys. With ACASI software, prerecorded audio files are played for each question and response option, and the respondent's answer is entered via an external numeric keypad. Because the respondent does not need to read the questions on the computer screen, s/he does not have to be literate or computer savvy to complete the survey. One important advantage of ACASI over face-toface (FTF) interviews is that neither the investigator nor anyone else in the area where the interview is being conducted hears the question asked or the response given, thus reducing the likelihood that adolescents will modify their answers to reduce embarrassment or to conform to social norms (Tourangeau et al. 2000; Turner et al. 1998). In addition, the characteristics and interviewing styles of the interviewers will not influence the survey process.

The Malawi study builds on an earlier experiment conducted as part of a household-based survey of Kenyan adolescents in which Population Council researchers investigated the feasibility of ACASI in rural Africa and assessed the improvement in data quality over face-to-face and paper-and-pencil self-administered questionnaires (Mensch et al. 2003; Hewett et al. 2004a, 2004b). The data were collected as part of an ancillary study to the Malawi Diffusion and Ideational Change Project, a panel survey of ever-married women of childbearing age and their husbands conducted by researchers from the Population Studies Center at the University of Pennsylvania. Interviews were conducted in June and July 2004 among a supplemental sample of 501 unmarried female adolescents aged 15-21 in rural areas of Balaka District, an area characterized by high rates of HIV infection, teenage pregnancy, risky sexual behaviors, and early sexual initiation. Respondents were randomly assigned either to an entirely face-toface interview or to a combination FTF/ACASI interview. To further minimize the effect of interviewer characteristics, all interviewers were female and trained in both interview methods, and respondents were randomized to an interviewer as well as to an interview mode. The sexual behavior questions began with a question on age at first sex and continued with questions about sex with different types of sexual partners, including an expected spouse, boyfriend, friend or acquaintance, relative, teacher, employer, and stranger. As in the Kenya study, the sexual partner questions were asked regardless of whether the respondent answered that she had "never had sex" when asked about her age at sexual initiation. After about a week, respondents were visited by a nurse who collected specimens for various sexually transmitted infections, including HIV, chlamydia, gonorrhea, and trichomoniasis. In addition to collecting the STI biomarkers, nurses conducted a short face-to-face interview in which they repeated certain questions about sexual behavior from the main survey.

\section{Results}

In Kenya and Malawi, there is clear evidence that the mode of interviewing and the probing of various sexual partnerships affect the reporting of sexual activity. Yet the results are not always consistent with initial expectations. Whereas it was expected that the greater privacy and confidentiality of the computerized ACASI interview would lead to higher reporting of all risky behaviors, in fact the percent reporting that they "ever had sex" and "ever had sex with a boyfriend" is higher in the faceto-face interview; in Malawi, the difference between the two interview types is substantial and statistically significant.

On the other hand, when asked about sex with other types of partners-particularly more stigmatized relationships-the percent reporting ever having sex is higher in ACASI. For instance, more than twice as many adolescents reported in ACASI that they had sex with an acquaintance (17 percent versus 7 percent), while seven times as many adolescents reported sex with a family member (7 percent versus 1 percent). Additionally, because ACASI respondents reported a higher likelihood of having sex with a stranger, a teacher, and/or an employer, the results from the two interview approaches revealed completely different portraits of sexual partnerships among adolescents. Whereas the vast majority of FTF respondents reported sex only with a boyfriend and/or expected spouse, over 40 percent of ACASI respondents reported sex with one of the other types of partners.

While ACASI produced higher reporting of relations with stigmatized partners, the FTF interviewer-administered mode produced more consistent reporting of sexual activity between the main interview and a subsequent face-to-face interview with nurses approximately one week later. Adolescents who reported that they did not have sex in a main interview conducted FTF were much more likely to give the same information to the nurses a week later ( 81 percent repeated their 


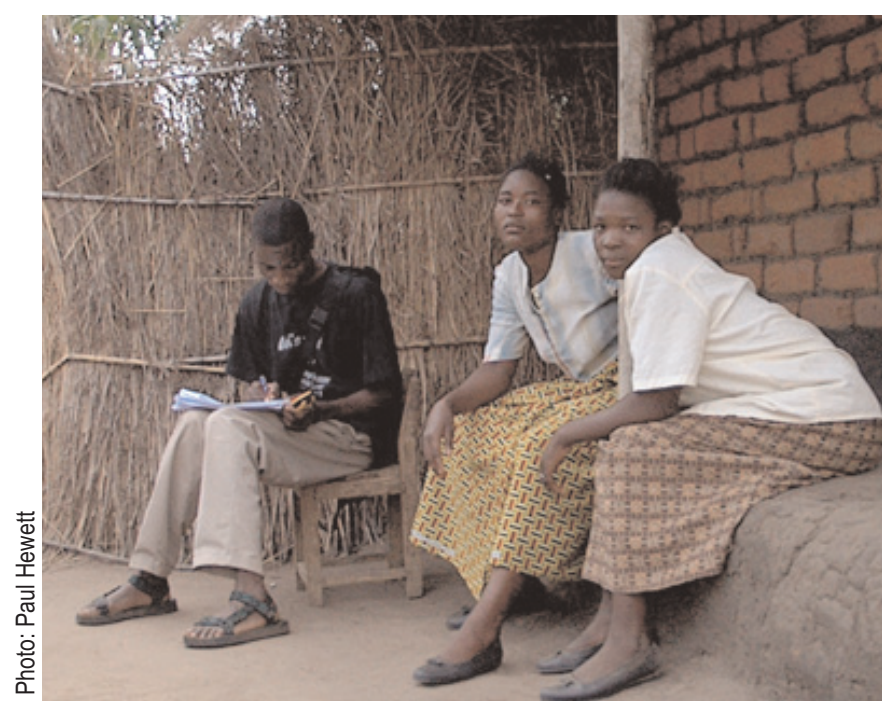

More research is needed to understand the role of face-to-face interviews in obtaining information on sensitive behaviors.

denial) than ACASI respondents (only 62 percent of whom maintained the same answer with the nurse). The greater proportion of those who denied having had sex in the ACASI interview and subsequently reported having had sex in the nurses' interview was neither anticipated nor fully understood.

The addition of STI/HIV biomarkers to survey data collection provides an external check on the validity of responses by allowing a direct comparison between risky behavior and STI/HIV outcomes. Such "triangulation" of reporting is an important tool for assessing the quality of data obtained in surveys. Although biomarkers were collected in Malawi, the ability to use them in this study was limited, given the relatively small sample from whom STI/HIV data were collected $(n=421)$ and the percent of respondents with missing STI/HIV data (16 percent). A positive and significant relationship between reporting having had sex and STI/HIV outcomes was observed in the face-to-face mode, but not in the ACASI mode, contrary to expectations. In both modes, there were "virgin" infections (10 percent in ACASI and 8 percent in FTF)-that is, young women who denied ever having sex who tested positive for STIS/HIV. Because the questions on sexual behavior used in this analysis do not capture recent STI/HIV risk particularly well, the results of the biomarker analysis are by no means conclusive.

\section{Implications for policy, programs, and research}

The AIDS pandemic has increased the need to gather comprehensive data on sexual behavior in developing countries. Inaccurate reporting of sexual and other risk behaviors hinders efforts to identify the underlying mechanisms driving the epi- demic and therefore can adversely affect intervention strategies to reduce transmission. In addition to distorting information on who in a given population is having sex, under what circumstances, with what STI/HIV protection, and with what degree of volition, inaccurate reporting leads to estimates of STI/HIV risk that are apt to be seriously biased.

Through projects in Kenya and Malawi, Population Council researchers have demonstrated that ACASI is a feasible methodology to use in rural areas of sub-Saharan Africa among adolescent populations unfamiliar with computers. Computerized interviewing generally improves the quality of data on highly sensitive behaviors collected from adolescents; however, the analyses from Kenya and Malawi also raised additional questions for future research. Given the importance of data on sexual behavior both in understanding the etiology of the AIDS epidemic and in the clinical testing of products and technologies to reduce the transmission of sexually transmitted infections, more research is needed on the interaction between interviewers and respondents and on reactions to the computer in developing-country populations.

\section{References and related publications}

Blanc, Anne K. and Naomi Rutenberg. 1990. "Coitus and contraception: The utility of data on sexual intercourse for family planning programs." Studies in Family Planning 22(3): 162-167.

Blanc, Ann K. and Ann A. Way. 1998. "Sexual behavior and contraceptive knowledge and use among adolescents in developing countries." Studies in Family Planning 29(2): 106-116.

Brewer, Devon D. et al. 2003. "(Review) Mounting anomalies in the epidemiology of HIV in Africa: Cry the beloved paradigm." International Journal of STD \& AIDS 14: 144-147.

Buvé, A. et al. 2001. "Interpreting sexual behaviour data: Validity issues in the multicentre study of factors determining the differential spread of HIV in four African cities." AIDS 15 (Supplement 4): S117-S126.

Cleland, J., J. T. Boerma, M. Carael, and S. S. Weir. 2004. "Monitoring sexual behaviour in general populations: A synthesis of lessons of the past decade." Sexually Transmitted Infections 80(Supplement II): ii1-ii7.

Curtis, S. L. and E. G. Sutherland. 2004. "Measuring sexual behaviour in the era of HIVIAIDS: The experience of Demographic and Health Surveys and similar enquiries." Sexually Transmitted Infections 80 (Supplement II): ii22-ii27.

Eggleston, E., J. Leitch, and J. Jackson. 2000. "Consistency of self-reports of sexual activity among young adolescents in Jamaica." International Family Planning Perspectives 26(2): 79-83. 
Gisselquist, David and John J. Potterat. 2003. "(Review) Heterosexual transmission of HIV in Africa: An empiric estimate." International Journal of STD \& AIDS 14: 162-173.

Gisselquist, David, John J. Potterat, Stuart Brody, and François Vachon. 2003. "(Review) Let it be sexual: How health care transmission of AIDS in Africa was ignored." International Journal of STD \& AIDS 14: 148-161.

Glynn, J. R. et al. 2001. "Why do young women have a much higher prevalence of HIV than young men? A study in Kisumu, Kenya and Ndola, Zambia." AIDS 15(Supplement 4): S51-S60.

Gregson, S. et al. 2004. "Informal confidential voting interview methods and temporal changes in reported sexual risk behaviour for HIV transmission in sub-Saharan Africa." Sexually Transmitted Infections 80 (Supplement II): ii36-ii42.

Gregson, Simon, Tom Zhuwau, Joshua Ndlovu, and Constance A. Nyamukapa. 2002. "Methods to reduce social desirability bias in sex surveys in low-development settings: Experience in Zimbabwe." Sexually Transmitted Diseases 29(10): 568-575.

Hewett, Paul C., Annabel S. Erulkar, and Barbara S. Mensch. 2004a. "The feasibility of computer-assisted survey interviewing in Africa: Experience from two rural districts in Kenya." Social Science Computer Review 22(3): 319-334.

Hewett, Paul C., Barbara S. Mensch, and Annabel S. Erulkar. 2004b. "Consistency in the reporting of sexual behavior among adolescent girls in Kenya: A comparison of interviewing methods." Sexually Transmitted Infections 80(Suppl 2): ii43-ii48.

Lagarde, Emmanuel, Catherine Enel, and Gilles Pison. 1995.

"Reliability of reports of sexual behavior: A study of married couples in rural West Africa." American Journal of Epidemiology 141(12): 1194-1200.

Mensch, Barbara S., Paul C. Hewett, and Annabel S. Erulkar. 2003. "The reporting of sensitive behavior by adolescents: A methodological experiment in Kenya." Demography 40(2): 247-268.

Mensch, Barbara S., Paul C. Hewett, and Richard Gregory. 2006. "Sexual behavior and STI/HIV status among adoles- cents in rural Malawi: An evaluation of the effect of interview mode on reporting." Submitted for inclusion in a special issue of Studies in Family Planning, devoted to selected papers from the International Seminar on Sexual and Reproductive Transitions of Adolescents in Developing Countries organized by the IUSSP Scientific Panel on Adolescent Life Course in Developing Countries and the Center for Demographic, Urban, and Environmental Studies, El Colégio de México Cholula, 6-9 November, Puebla, Mexico.

Nnko, Soori et al. 2004. "Secretive females or swaggering males? An assessment of the quality of sexual partnership reporting in rural Tanzania." Social Science \& Medicine 59(2): 299-310.

Plummer, M. L. et al. 2004. "A bit more truthful': The validity of adolescent sexual behaviour data collected in rural northern Tanzania using five methods." Sexually Transmitted Infections 80(Supplement II): ii49-ii56.

Tourangeau, R., L. J. Rips, and K. Rasinski. 2000. The Psychology of Survey Response. Cambridge, England: Cambridge University Press.

Turner, C. F. et al. 1998. "Adolescent sexual behavior, drug use and violence: Increased reporting with computer survey technology." Science 280: 867-873.

Zaba, B., E. Pisani, E. Slaymaker, and J. Ties Boerma. 2004. "Age at first sex: Understanding recent trends in African demographic surveys." Sexually Transmitted Infections 80(Supplement II): ii28-ii35.

\section{Donors}

Department for International Development (DFID); The William and Flora Hewlett Foundation; National Institutes of Health; Bureau for Global Health, USAID

Partner Institutions

Population Studies Center, University of Pennsylvania

Research Collaborators

Stephane Helleringer, Hans-Peter Kohler, Susan Watkins

For more information or for copies of other briefs, contact publications@popcouncil.org For additional resources see www.popcouncil.org/pgy

Population Council

One Dag Hammarskjold Plaza

New York, New York 10017 USA

(c) 2007 by The Population Council, Inc. 